Marquette University

e-Publications@Marquette

College of Nursing Faculty Research and

Publications

Nursing, College of

2020

Escalation: Raising the College Students' Awareness Regarding

Early Signs Of Abusive Relationships

Abir Bekhet

Courtney A. Kailunas

Alina T. Atayan

Follow this and additional works at: https://epublications.marquette.edu/nursing_fac

Part of the Nursing Commons 


\title{
Escalation: Raising the College Students' Awareness Regarding Early Signs of Abusive Relationships
}

\author{
Abir K. Bekhet, Courtney A. Kailunas', Alina T. Atayan² \\ Marquette University College of Nursing, Milwaukee, WI, 'University of Florida College of Nursing, Gainesville, Florida, USA, ${ }^{2}$ St. Luke's Medical Center, \\ Milwaukee, WI, USA
}

\section{Abstract}

Background: Abusive relationships are highly prevalent in our society, but often go unnoticed. Research showed that dating violence continues to escalate in college student populations. Purpose: The purpose of this study is to determine the effectiveness of the video as a chosen method of education in raising the college students' awareness regarding warning signs of an abusive relationship. Design: This study used a descriptive qualitative design. Sample/Data Collection: Five focus groups of college students' participants (freshmen to seniors) were recruited to participate in the "Escalation" workshop. To facilitate discussion, each focus group originally had 15 college students for a total of 75 college students' participants. Five participants dropped of the study the last minute due to conflicting schedules and personal situations. Each focus group lasted for $90 \mathrm{~min}$ and consisted of watching a $38 \mathrm{~min}$ "Escalation" video that depicts scenarios of abusive relationships and a pre- and a post-qualitative discussion. Results: The results of the study and the identified themes illustrate the broadened perspectives participants gained through participating in the workshop. Insights from participants became less focused on physical abuse and began to include more mental and emotional effects of abuse in their responses. This study showed that most participants were not previously aware of the progression and scope of violent relationships. Discussion/Conclusion: By recognizing the early signs of an abusive relationship, it is more likely for victims and/or peers to intervene in a safe manner rather than continuing to allow an abusive relationship to escalate to its full potential of violence and physical harm.

Keywords: Abusive relationships; college students; controlling behaviors; warning signs

\section{INTRODUCTION}

Abusive relationships are highly prevalent in our society, but often go unnoticed. ${ }^{[1]}$ Abuse is defined as the "intentional use of physical force or power, threatened or actual, against another person that either result in or has a high likelihood of resulting in injury, death, psychological harm, maldevelopment or deprivation." ${ }^{[2,3]}$ An abusive relationship can be physical, sexual, or psychological. ${ }^{[4]}$ Statistics show that 1 in 3 women and 1 in 4 men will be in an abusive relationship in their lifetime. ${ }^{[5]}$ The National Intimate Partner and Sexual Violence Survey showed that over $35 \%$ of women and more than $28 \%$ of men reported rape and physical assault by an intimate partner during their lifetime. ${ }^{[6]}$ However, these percentages are only a small fraction of the actual number of victims of violent intimate relationships. ${ }^{[6,7]}$ According to the Centers for Disease Control and Prevention, the highest risk

Received: 07-08-2019; Accepted: 06-12-2019; Published: 03-03-2020.

\begin{tabular}{|l|l|}
\hline \multicolumn{2}{|c|}{ Access this article online } \\
\hline Quick Response Code: & Website: \\
& www.heartmindjournal.org \\
\cline { 2 - 2 } & \\
\hline
\end{tabular}

group for this violence is those aged $18-24$ years old, and about 1 in 9 female and 1 in 36 male high school students report sexual dating violence. ${ }^{[6,8]}$

Relationship violence is defined as a pattern of behavior in an intimate relationship that is used to exert power and control over another person through fear and coercion, and this includes Dating violence. ${ }^{[9]}$ Victims of relationship violence tend to stay in the relationship for extended period because, in most circumstances, they are unaware of the abusive relationship until they are physically harmed. ${ }^{[10]}$

Research showed that dating violence continues to escalate in college student populations. ${ }^{[1]}$ Previous research

Address for correspondence: Dr. Abir K. Bekhet, Marquette University College of Nursing, Clark Hall 530 N. $16^{\text {th }}$ Street, Milwaukee, Wi 53233, USA E-mail: abir.bekhet@marquette.edu

This is an open access journal, and articles are distributed under the terms of the Creative Commons Attribution-NonCommercial-ShareAlike 4.0 License, which allows others to remix, tweak, and build upon the work non-commercially, as long as appropriate credit is given and the new creations are licensed under the identical terms.

For reprints contact: reprints@medknow.com

How to cite this article: Bekhet AK, Kailunas CA, Atayan AT. Escalation: Raising the college students' awareness regarding early signs of abusive relationships. Heart Mind 2020;4:1-6. 
also indicated that some students believe in violence myths. ${ }^{[7]}$ Therefore, educating college students through peer-facilitated group discussions is essential in raising the college students' awareness of the warning signs of abusive relationships to prevent its harmful consequences. ${ }^{[10]}$ Given the higher prevalence of abusive relationship in our society and the lack of awareness about the early signs of abusive relationships among college students, preventative measures need to be taken to help raising the college students' awareness of warning signs of abusive relationships. The previous research showed that one in four college students were involved in a physically abusive dating relationship and over $85 \%$ of college students failed to self-identify as ever having received and/or perpetrated any act of physical abuse in a sample of 1530 university students between the ages of $18-25$ years. ${ }^{[12]}$ In fact, educating this high-risk group will have a positive outcome in terms of preventing the physical, emotional, and the mental consequences of the abusive relationships as well as saving many of the lives of those who get abused. ${ }^{[10]}$

Since students will be educated about a spectrum of warning signs, through this learning tool, they will be able to identify an abusive relationship during various stages. By raising awareness about relationship violence as well as their early signs, students will feel empowered. Many times, people will disconcert signs of potential abuse until it is too late, and they or a loved one are being physically harmed. By providing them with this education, we are helping in preventing domestic violence, as it will help diffuse the relationship before it escalates to a point of physical abuse. Our study also helps two groups of people, victims, and bystanders. This is important as these groups will connect in real life. By educating those who may be potential victims, we are helping to empower them and by educating bystanders we are helping this group make a difference in the life of a potential victim. Many times, victims feel alone and that they cannot reach out to a peer about the matter. By educating both groups, we are creating a cohesive community of students, who are well educated, understand the domestic violence, and know how to diffuse it in a safe manner for all parties, thus illuminating domestic violence and stopping it before it begins. ${ }^{[10]}$

Previous research investigated college students' perceptions and participation in abusive dating relationships ${ }^{[12]}$ and examined the connection between the understanding of sexual consent and perpetration of sexual aggression. ${ }^{[13]}$ Previous research also assessed perceived control, hopelessness, self-esteem, and optimism in 280 college students involved in abusive and nonabusive relationships. ${ }^{[11]}$ However, previous research did not investigate the impact of using a video as a method of education on raising the college students' awareness regarding early signs of abusive relationship as proposed in this study. Therefore, the purpose of this study is to determine the effectiveness of the video as a chosen method of education in raising the college students' awareness regarding warning signs of abusive relationship. This study will provide information about what participants find most helpful, information learned, and what they personally think could improve the method of domestic violence prevention education.

\section{Methods}

\section{Design}

This study used a descriptive qualitative design.

\section{Participants}

Five focus groups of college students' participants (freshmen to seniors) were recruited to participate in the "Escalation" workshop. To facilitate discussion, each focus group originally had 15 college students for a total of 75 college students' participants. Five participants dropped out of the study the last-minute due to conflicting schedules and personal situations (two dropped from the first focus group, two from the second focus group, and one from the fourth focus group). Therefore, the final sample includes 70 university students' participants.

The inclusion criteria included being a current university student (freshmen to seniors). Each focus group lasted for $90 \mathrm{~min}$ and consisted of watching a $38 \mathrm{~min}$ "Escalation" video that depicts scenarios of abusive relationships and a pre- and a post-qualitative discussion focusing on:

1. What is relationship violence?

2. What are the warning signs of an abusive relationship?

3. Who is most likely to suffer from relationship violence or become a victim of abusive relationship?

Following the workshop (i.e., escalation film and designated workshop discussion questions), the following questions were asked:

1. What did you learn from this workshop?

2. What parts of the workshop were most and least helpful?

3. What is your inclination to act after this workshop?

\section{Data collection procedure}

Approval for the study was obtained from the University Institutional Review Board (IRB). An IRB-approved flyer was posted across campus. Those who are interested contacted the research assistants. On an agreed on date and time, the research assistants provided information about the purpose of the study, protection of confidentiality, and the data collection procedure. Participants had the opportunity to ask any questions about the study prior to the start of the focus group. Participants were asked to read a consent form for the study, and they were informed that their responses would be audio-recorded and transcribed. Participants were given nametags with fake names to protect their identity during the workshop and study discussion questions. Each participant received a \$20 gift card at the end of the workshop. A list of participant's names, written responses, and audio recorded responses were kept in a locked and secure drawer. Data were collected in fall 2017. Due to students' busy schedules, the sessions took place over the weekend in one of the classrooms as most students live on campus. 


\section{The workshop}

The workshop was developed by the One Love Foundation. ${ }^{[10]}$ One Love Foundation was created in 2010 to honor the memory of Yeardley Love, a senior at the University of Virginia, who was physically beaten to death by her ex-boyfriend weeks short of graduation. The "Escalation" workshop was developed by professors from Boston University School of public health, Michigan State University, and the One Love Foundation. ${ }^{[10]}$ The researcher and the research assistants received training by One Love Foundation. The training includes the film's concepts, trigger warnings, workshop discussion questions/potential responses, and how to direct and enable open student discussion.

The $38 \mathrm{~min}$ "Escalation" film tells the story of an abusive relationship case from its beginnings to its tragic end. The authentic depiction of unhealthy behavior escalating into violence shed the light on abusive relationships and help students to understand and recognize the early signs of relationship abuse. ${ }^{[10]}$ This training is provided by the One Love Foundation to all those who desire to lead an Escalation Workshop to provide consistent means of education to students across the country.

\section{Data analysis}

The credibility of the data was achieved by independent coding of the data by the three researchers individually, with a percentage agreement that exceeded $95 \%$ while comparing the coding, the categorization, and the major findings. The three researchers used content analysis to study the categories across participants. Creating a category is an important element of qualitative content analysis. A category is defined as a group of content that shares a commonality. ${ }^{[14]}$ Content analysis was performed as follows: Reading the transcripts, coding the data, and identifying the categories in each participant's response and then re-reading the responses to find out similar categories across participants. ${ }^{[14]}$ To ensure the trustworthiness of findings, the three researchers met and compared the interpretations of the responses until they reached a consensus on the major findings from the students' responses as an iterative process $^{[15]}$ (Struebert and Carpenter, 1999). ${ }^{[16]}$ Credibility and truthfulness are also enhanced through the use of the student's quotations as a mean of reflecting the accurate descriptions of their experiences. ${ }^{[17]}$ Saturation was also achieved as there was no new themes arose from the students 'experiences. ${ }^{[17]}$

\section{REsULTS}

Seventy students participated in the study. Sixty students were females and ten were males. Their ages range between 18 and 25 years old. Eighty percent of participants were Caucasian. Other races include; Hispanics, Middle Easterners, and African Americans.

The findings were structured into three major findings (categories) that will be addressed before and after watching the movie:
1. Scope of relationship violence and early and subtle signs of an abusive relationship

2. Victims of abusive relationship

3. "Escalation" workshop evaluation.

a. What did you learn from this workshop?

b. What parts of the workshop were most and least helpful?

c. What is your inclination to act after this workshop?

Scope of relationship violence and early and subtle signs of abusive relationship

before watching the video

Theme 1: Physical abuse

Ninety percent of participants mainly focused on the physical abuse aspects of relationship violence before watching the video. Examples of their definitions included:

"I said that relationship violence is when a partner in a relationship is experiencing physical abuse from the other involved partner, just because violence makes me think more of physical abuse."

“...Physical things, like hitting, slapping or sexual assault."

"I also said bruises or odd marks can be signs of physical abuse."

\section{After watching the video}

Theme 1: Emotional and mental manipulation

Eighty-five percent of participants noted that they found relationship violence to be much more than just physical violence. Students noted that relationship violence could also be in the forms of emotional and mental manipulation, as these were the tactics most often used by the perpetrator of the violence. Examples of their responses included:

"I'd add there's a level of intimidation from the abuser and it can include things like threatening self-harm or threatening to harm the other party."

"Making them feel worthless, building up trust and betraying the trust, and then treating them abusively, and then going back and forth between like abuse and love, treating them that way."

\section{Theme 2: Controlling behaviors}

The signs of abuse became broader after the individuals viewed the film, as they noted a wider variety of signs that a victim or abuser may display.

"For the abuser, it's more like controlling behavior, like asking for location, jealousy, showing up unannounced, overstepping clear boundaries and great outbursts. And like the victim again, it's like withdrawn, baggy clothes, like not talking about it, stuff like that."

"Having to know the other partner's whereabouts at all times and like who they're with definitely is really, really controlling and a lot of the time, it's really just the partner and I guess the victim in this case, they're spending all their time and like constant messaging as well." 


\section{Theme 3: Warning and subtle signs}

"I said some of the warning signs, like for both the victim and the abuser, are like-like not talking about it when asked or avoiding the issue."

"like in the movie it showed that she like was not really paying attention to her friends and I think that's important to see-like she was almost afraid to hang out with her friends, so it had like. a lot of social repercussions and also like psychological, like she was like even afraid just to go home and be with the people that she actually loves, and I think that's important to look at too."

"I don't know if you guys caught it where he was like you need to change your pants because you look fat in them. Like I was like okay, like I don't know if you meant to say that or not, but like she never really responded to it, so like that's kind of an example of that, I thought."

"So, I said distancing from friends and family, yelling or arguing, emotional distress or defensiveness because I feel like when you're in an abusive relationship, you often don't realize you're in an abusive relationship, so when people try to give you identifying signs or like talk to you about it, you often like doubt and like get really defensive about it."

Initially, a majority of participants noted signs of relationship violence that were physical in nature, such as physical harm, neglecting appearance, and signs of bruising on the victim. On taking part in the workshop, film and discussion, participants identify more of the subtle signs of relationship violence.

Examples of subtle and early signs of abuse that were captured after watching the movie included: students cited specific examples from the film of the abuser manipulating the victim in the relationship. The film assisted in identifying the behaviors in an abusive relationship that would be harder to identify otherwise. Furthermore, students were able to explain the controlling types of behaviors an abuser may utilize when interacting with the victim. Emotional distancing from friends and family was another aspect of abusive relationships that was identified by the students after watching the film. This aspect of abuse was not mentioned by participants before viewing the film.

\section{Victims of relationship violence}

Prior to watching the film, most participants noted that a victim of relationship violence was most likely to be a young woman, especially between the ages of 18 and 25 years. Examples are:

"I would say college women."

"Women are most likely to suffer the abuse in a relationship."

"Women ...especially college ages."

"Younger women especially in the college."

After viewing the movie, participants added on to their answers to include all persons in whom would be most likely to be affected by relationship violence.
"I believe that like anyone is like able to be a victim of a relationship violence, regardless of like what you said earlier, like heterosexual, like men, women, children, everyone is really able to be part of a relationship-abusive tendency."

Ultimately, participants became aware that anyone can be a victim of relationship violence and attributed the influence of the media to the depiction of women being more likely victims.

"Anyone can be a victim and just the way the media portrays sexual violence and relationship violence, women are usually the more common factor, but they never really highlight men or anything, or like young boys like that either, but obviously, it happens, the media just doesn't highlight it as much."

\section{Escalation workshop evaluation}

What did you learn from this workshop?

The theme identified out of most participants' responses is "eye opener." Examples of participant's responses are as follows:

"It just opened my eyes to how subtle it can be at first before it escalates, like just-it-it doesn't have to seem like a big deal at first, but then it is."

"I honestly didn't realize how many young college girls have actually died from this."

"I learned that like anyone can be a victim of relationship violence and like the importance of not ignoring the signs."

"Definitely, I didn't realize how common relationship violence is."

What parts of the workshop were most and least helpful? Participants indicated that the video and the discussions were the most helpful, and

they did not identify anything as least helpful. Examples of participants' responses included:

"Just overall, like I think the video was really well done and helpful."

"Watching the video is probably the most helpful and like seeing the warning signs of an abusive relationship. I didn't find anything that was like least helpful. And then most interesting, I think like sitting here and like discussing it is like really interesting in hearing what other people like have to say, like-I mean, I don't know all of you, but I just think it's like interesting to get different perspectives."

\section{What is your inclination to act after this workshop?}

"You should always speak up when you see signs of it, even if you know the person might be mad at you or respond poorly to you for it."

"And-that you might see from like friends and family, and being able to speak up for like yourself or like for other people that you see in an abusive relationship."

"I really want to speak up to either my friend that's like in the relationship or speak up to someone else to get them help, and I'd really love to get involved with One Love, to learn how to 
like spread awareness of relationship violence, because I think it's super important to get knowledge out."

"The first 3 weeks of college is like called the red zone, where like a college student is more likely to be assaulted their freshman year, like in the first 3 weeks, so I think it's really important."

\section{DISCUSSION}

To date, this is the first study that evaluated the impact of watching a video along with facilitating discussions by peers as a method of learning about abusive relationships. This study is innovative as it focuses on raising the college students' awareness of warning signs of domestic violence and uses a video as a learning tool. The previous research showed that using a video as a learning tool together with a subsequent discussion was different and powerful as compared to reading books or ordinary practice from students' perspectives ${ }^{[18]}$ Furthermore, using peer discussion is an essential learning tool to empower adolescents. ${ }^{[10]}$ The results of our current project with college students are aligned with previous research showing that video as a learning tool with subsequent peer discussion was powerful in helping college students identifying the signs of relationship violence more effectively.

Results showed that participants were not previously aware of the progression and scope of violent relationships. The participants noted that they felt better equipped to identify the signs of relationship abuse if they felt that their friend or a family member was in such a situation. The realization of the complexity of the situations that come with relationship violence was noted by the participants to help them identify the signs of relationship violence more effectively. This study showed that video, as a learning tool, along with discussion by peers is an effective and impactful method to educate peers about relationship abuse.

The results of the study and the identified themes illustrate the broadened perspectives participants gained through participating in the workshop. Insights from participants became less focused on physical abuse and began to include more mental and emotional effects of abuse in their responses. This study showed that most participants were not previously aware of the progression and scope of violent relationships. Being able to follow along the progression through a film provided participants with substantive topics and details to discuss that they might not have been able to previously. The discussion aspects of the workshop is also important as it allows participants of the same demographic as the common victims of relationship violence to openly dissect the early signs of an unhealthy relationship as well as determines when it has become abusive in nature.

By combining the film and peer discussion into one workshop, as the One Love Foundation has done, students are able to witness behaviors and actions in full context and have the ability to bring up a multitude of traits and themes that most commonly occur in abusive relationships.

While this workshop and study were primarily focused on abusive relationships, this means of education can be deemed useful for other topics of interest. In today's society, there are many topics of interest such as mental health concerns that society merely sees the tip of the iceberg to as they have limited experience or exposure, especially if they are of a younger or narrow demographic. This study showed that using a film and discussion model as means of education, is a beneficial and impactful way of learning.

The limitations of this study include the use of a convenience sample as some students might not be available on campus at the time of the focus groups or they might be taking online classes. Hence, the findings might not represent all students. Another limitation is that the study took place in one university, most of its students are White Caucasian. Therefore, future research should include students of various ethnic backgrounds to represent their perspectives as well as future research should consider including more than one university. Furthermore, the research took place in a private Jesuit university. Therefore, the findings might not apply to other public universities. Future research should consider replicating the research in public schools. Future research might consider a methodological triangulation approach (i.e., combining quantitative and qualitative methods) to look at other factors such as age, sex, marital status, and its impact on awareness of dating violence. Future research might also consider measuring the difference between watching the movie with and without further discussion in helping the students to capture the early signs of abusive relationship.

Despite its limitations, this research helped in raising the college students' awareness regarding early signs of abusive relationship and shed the light on mental and emotional effects of abuse that many participants were not aware of.

\section{Conclusion}

Education on the topic of relationship abuse has been neglected among the demographic in which it statistically affects the most directly, i.e., college-aged students 18-24 years of age. Students have expressed through this study that they were unaware of signals, other than blatant signs of physical abuse such as bruises and cuts. It was determined through this study that after watching a carefully researched and vetted film and experiencing a guided discussion provided by the One Love Foundation, that participants were able to determine early warning signs and themes in abusive relationships. By being able to recognize these traits, participants are more likely to notice these warning signs in their own lives. By recognizing the early signs of an abusive relationship, it is more likely for victims and/or peers intervene in a safe manner rather than continuing to allow an abusive relationship to escalate to its full potential of violence and physical harm. 


\section{Acknowledgment}

The authors would like to acknowledge One Love Foundation for the training and for providing us with the video that was used in the study.

\section{Financial support and sponsorship}

The study was funded by Marquette University Strategic Innovation Fund Award awarded to Dr. Abir K. Bekhet and her team.

\section{Conflicts of interest}

There are no conflicts of interest.

\section{RefEREnCES}

1. Voth Schrag RJ. Campus based sexual assault and dating violence: A review of study contexts and participants. Affilia 2017;32:67-80.

2. Scott-Storey KA, Hodgins M, Wuest J. Modeling lifetime abuse and cardiovascular disease risk among women. BMC Cardiovasc Disord 2019;19:224.

3. World Health Organization. World Report on Violence and Health. Geneva: World Health Organization; 2002.

4. Scott-Storey K. Cumulative abuse: Do things add up? An evaluation of the conceptualization, operationalization, and methodological approaches in the study of the phenomenon of cumulative abuse. Trauma Violence Abuse 2011;12:135-50.

5. National Coalition against Domestic Violence: Domestic violence national statistics; 2015. Available from: http://www.ncadv.org. [Last retrieved on 2018 Aug 02].

6. Black MC, Basile KC, Breiding MJ, Smith SG, Walters ML, Merrick MT, et al. The National Intimate Partner and Sexual Violence Survey: 2010 Summary Report. Atlanta, A: National Center for Injury Prevention, Centers for Disease Control and Prevention; 2011.

7. Policastro C, Payne BK. The blameworthy victim: Domestic violence myths and the criminalization of victimhood. J Aggress Maltreat Trauma 2013;22:329-47.

8. Breiding MJ, Basile KC, Smith SG, Black MC, Mahendra RR. Intimate Partner Violence Surveillance: Uniform Definitions and Recommended data Elements, Ver. 2.0. Atlanta, GA: National Center for Injury Prevention and Control, Centers for Disease Control and Prevention; 2015.

9. Chhikara P, Jakhar J, Malik A, Singla K, Dhattarwal SK. Review research paper domestic violence: The dark truth of our society. J Indian Acad Forensic Med 2013;35:971-3.

10. Rothman E, Bonomi A, Sullivan C, Sperling M, Robinson S, \& Hood, K. Discussion Guide for the Training Video Escalation. New York, NY: The One Love Foundation; 2015. Available from: http://www.joinonelove. org. [Last retrieved on 2018 Aug 02].

11. Clements C, Ogle R, Sabourin C. Perceived control and emotional status in abusive college student relationships: An exploration of gender differences. J Int Violence 2005;20:1058-77.

12. Miller LM. Physical abuse in a college setting: A study of perceptions and participation in abusive dating relationships. J Fam Violence 2011;26:71-80.

13. Warren P, Allen CT. Comprehension of sexual consent as a key factor in the perpetration of sexual aggression among college men. J Aggress Maltreat Trauma 2015;24:897-913.

14. Graneheim UH, Lundman B. Qualitative content analysis in nursing research: Concepts, procedures and measures to achieve trustworthiness. Nurse Educ Today 2004;24:105-12.

15. Matel-Anderson DM, Bekhet AK. Resilience in adolescents who survived a suicide attempt from the perspective of registered nurses in inpatient psychiatric facilities. Issues Ment Health Nurs 2016;37:839-46.

16. Struebert HJ, Carpenter DR. Qualitative research in nursing: Advancing the humanistic imperative. Philadelphia: Lippincott Williams \& Wilkins. 1999

17. Guba EG, Lincoln YS. Fourth Generation Evaluation. NewburyPark CA: Sage; 1989.

18. Stiberg E, Holand U, Olstad R, Lorem G. Teaching care and cooperation with relatives: Video as a learning tool in mental health work. Issues Ment Health Nurs 2012;33:528-35. 